\title{
Occult anastomotic leakage after rectal resection in patients with diverting stoma: Exploring optimal indications and examination of early stoma closure
}

\section{Daichi Kitaguchi \\ Tsukuba Daigaku \\ Tsukuba Daigaku \\ Yusuke Ohara \\ Tsukuba Daigaku \\ Yohei Owada \\ Tsukuba Daigaku \\ Katsuji Hisakura \\ Tsukuba Daigaku \\ Yoshimasa Akashi \\ Tsukuba Daigaku \\ Kazuhiro Takahashi \\ Tsukuba Daigaku \\ Koichi Ogawa \\ Tsukuba Daigaku \\ Osamu Shimomura \\ Tsukuba Daigaku \\ Tatsuya Oda \\ Tsukuba Daigaku}

Tsuyoshi Enomoto ( $\nabla$ eno@md.tsukuba.ac.jp )

\section{Research article}

Keywords: diverting stoma, loop ileostomy, anastomotic leakage, rectal resection, early closure

Posted Date: December 17th, 2019

DOI: https://doi.org/10.21203/rs.2.18766/v1

License: (1) This work is licensed under a Creative Commons Attribution 4.0 International License.

Read Full License 
Version of Record: A version of this preprint was published at BMC Surgery on March 19th, 2020. See the published version at https://doi.org/10.1186/s12893-020-00706-X. 


\section{Abstract}

\section{Background}

In the immediate postoperative period, neither have the incidence and risk factors of occult anastomotic leakage (AL) in patients with diverting stoma (DS) been clarified, nor have methods to assess anastomosis been standardized. Before introducing "early stoma closure", both standardized inclusion and exclusion criteria and standardized methods to assess anastomosis are necessary. The aim of this study was to elucidate the incidence and risk factors of occult $A L$ in patients who had undergone rectal resection with DS and to evaluate the significance of computed tomography (CT) following water-soluble contrast enema (CE) to detect occult anastomotic leakage.

\section{Methods}

This was a single institutional prospective observational study of patients who had undergone rectal resection with DS between May and October 2019. All patients had undergone CE and CT to assess for anastomosis on postoperative day (POD) 7, and CT was performed just after CE. Univariate analysis was performed to assess the relationship between preoperative variables and the incidence of occult $A L$ on POD 7

\section{Results}

The incidence of occult AL on postoperative day 7 was $40 \%$. Hand-sewn anastomosis, compared with stapled anastomosis, was a statistically significant risk factor $(p=0.0406)$. Five more cases with occult AL that could not be detected with CE could be detected on CT following CE; CE alone had a $33 \%$ falsenegative radiological result rate.

\section{Conclusions}

Hand-sewn anastomosis was a risk factor for occult AL, and CE alone had a high false-negative radiological result rate. When considering the introduction of early stoma closure, stapled anastomosis and CT following CE could be an appropriate inclusion criterion and preoperative examination, respectively.

\section{Background}

A diverting stoma (DS) is used primarily to protect the anastomosis and prevent pelvic sepsis after rectal surgery [1]. Several studies have shown that a particular benefit of DS is the reduction in the number of leaks requiring surgery [2-6]. As a DS, loop ileostomy is preferred to colostomy by most surgeons because the former is easy to construct and close without the risk of injury to the colic vascular arcade, and there are fewer problems with prolapse [7]. 
Previous studies have shown complications of DS with rates up to $43 \%$ related to the loop ileostomy, including outlet obstruction, readmissions, dehydration due to high output, and chronic renal failure [810]. In addition, patients with rectal cancer are increasingly being offered postoperative adjuvant therapy, which creates uncertainty about the timing of DS closure [11].

A multicenter randomized controlled trial, EASY, showed that early DS closure (EC) significantly reduced postoperative morbidity, especially stoma-related complications, including skin irritation, stomal ulcer, and leakage outside the appliance bag [12]. A meta-analysis also showed that there was no significant difference between EC and late DS closure (LC) group in the incidence of anastomotic leakage (AL) and reoperation [13]. However, in the literature, approximately one-third of patients were deemed inappropriate for early reversal $[14,15]$; in the EASY trial, the exclusion rates reached two-thirds of patients because of the strict exclusion criteria, including diabetes mellitus (DM) and steroid treatment [12].

EC has not been widely adopted as a standard treatment strategy. In the early postoperative period, the incidence and risk factors of occult $A L$ in patients who had undergone rectal resection with $D S$ have not been clarified. Methods to assess anastomosis have also not been standardized, and a false-negative radiological result may lead to performing inadequate $E C$ for patients with occult $A L$, thereby increasing the risk of anastomotic septic complications. Therefore, both standardized inclusion and exclusion criteria and standardized methods to assess anastomosis are necessary to perform EC safely.

The aim of this study was to clarify the incidence and risk factors of occult AL in patients who had undergone rectal resection with DS and to consider the significance of computed tomography following water-soluble contrast enema to detect occult AL

\section{Methods}

\section{Demographics}

All patients who had undergone rectal resection with a DS between May and October 2019 were enrolled in our prospective, single-center institutional database. The standard indication of DS at our institute is that the anastomotic level from the anal verge is approximately $5 \mathrm{~cm}$ or less. All patients were scheduled to undergo stoma closure several months after the initial surgery, and the subsequent treatment strategy was not affected by the results of this study.

All patients underwent digital rectal examination (DRE), water-soluble contrast enema (CE), and computed tomography (CT) to assess the anastomosis. These three examinations were performed on postoperative day (POD) 7, and CT was performed just after CE. Hematological examinations, including estimation of white blood cell counts (WBC) and C-reactive protein (CRP) levels, were also performed on POD 7 to assess inflammatory status.

CE was performed by an experienced colorectal surgeon using $100 \%$ Gastrografin $\circledast$ as the contrast medium. The contrast medium was instilled using a Nelaton catheter placed in the rectum just below the 
anastomosis. The amount of contrast medium infused was 50-100 mL, and when leakage of contrast medium was detected extraluminally, the examination was immediately stopped.

Pelvic plain CT without contrast medium was performed by an experienced colorectal surgeon.

Data were collected through electronic medical record systems. Patient characteristics included age, sex, body mass index (BMI), previous abdominal operations, American Society of Anesthesiology physical status (ASA-PS) classification, smoking history, DM, and primary disease. Treatment characteristics included preoperative treatment, operation, minimally invasive surgery (MIS), anastomosis, and distance of the anastomosis from the anal verge (AV).

\section{Statistical Analysis}

Quantitative data were reported as median [range] and compared using the Mann-Whitney U test. Qualitative data were reported as the number of patients (percentage) and compared using Fisher's exact test, as appropriate. All tests were two-sided, with the level of significance set at $p<0.05$. All statistical analyses were performed with EZR (Saitama Medical Center, Jichi Medical University, Saitama, Japan), which is a graphical user interface for $\mathrm{R}$ (The R Foundation for Statistical Computing, Vienna, Austria). EZR is a modified version of $\mathrm{R}$ commander designed for statistical functions frequently used in biostatistics [16].

\section{Results}

During the study period, 15 patients underwent rectal resection with a DS. Patient characteristics are detailed in Table 1.

The median age of the cohort was 56 years [27-70], with $80 \%$ of patients being male. The median BMI was $24 \mathrm{~kg} / \mathrm{m}^{2}$ [18-39], and most (67\%) patients' ASA-PS classification was 2.

Sixty-seven percent of patients had a history of smoking, and $13 \%$ of patients had DM. Regarding primary disease, the proportion of rectal cancer, ulcerative colitis (UC), and familial adenomatous polyposis (FAP) was $67 \%, 27 \%$, and $7 \%$, respectively.

Treatment characteristics are detailed in Table 2. Twenty percent of patients underwent chemoradiotherapy (CRT), and $13 \%$ of patients were treated with a steroid. Regarding the type of operation, the proportions of low anterior resection (LAR), intersphincteric resection (ISR), and total colectomy with ileal pouch-anal anastomosis (IPAA) were $27 \%, 40 \%$, and $33 \%$, respectively. A transanal total mesorectal excision (TaTME) was performed for $53 \%$ of patients, and robotic surgery was performed in only one case.

The proportion of stapled anastomosis and hand-sewn anastomosis was $53 \%$ and $47 \%$, respectively, and the median distance of anastomosis from the AV was $4 \mathrm{~cm}[2-6]$. 


\section{Incidence and Risk Factors of Occult AL}

With DRE alone, it was difficult to detect occult AL. Even with water-soluble CE, only one case $(7 \%)$ of occult AL was successfully detected in this study. With $C T$ following $C E$, the incidence of occult $A L$ on POD 7 increased to $40 \%$.

The relationship between each variable and the incidence of occult AL on POD 7 has been summarized in Table 3. The incidence of occult AL was $71 \%$ in the hand-sewn anastomosis group and $13 \%$ in the stapled anastomosis group, which reached a statistically significant difference $(p=0.0406)$. The other variables had no statistically significant correlation with the incidence of occult AL.

There were no significant correlations between occult $A L$ and the results of hematologic examination (Table 4), and all patients who were diagnosed with occult AL had no symptoms associated with AL during their postoperative course.

\section{Discussion}

In patients who had undergone rectal resection with a DS, the incidence of occult AL on POD 7 was $40 \%$, and compared with stapled anastomosis, hand-sewn anastomosis, was a statistically significant risk factor. With DRE and CE alone, it was difficult to detect occult $A L$, and five more cases with occult $A L$ that could not be detected with CE alone were detected with CT following CE. In other words, CE alone had a $33 \%$ false-negative radiological result rate in this study.

Alves et al. reported that a $7.5 \%$ false-negative radiologic result rate leads to re-intervention in two-thirds of these patients in their randomized clinical trial of EC vs LC [14]. In the trial, antegrade water-soluble CE through the distal limb of the DS was performed on POD 7, and the retrograde (transanal) approach was not used to avoid potential anastomotic injury; however, this risk remains unproven. Gouya et al. reported that CT antegrade colonography was more accurate than antegrade fluoroscopy for evaluation of both low anastomosis and surrounding space patency [17]. Danielsen et al. reported no false-negative radiologic results using $\mathrm{CT}$ with water-soluble CE [12].

Careful selection of the patients remains crucial to maintaining low overall postoperative morbidity, which is the aim of an early stoma reversal. In this regard, imaging plays a pivotal role because a false-negative radiologic result may lead to inadequate $\mathrm{EC}$, thereby increasing the risk of anastomotic septic complications. Considering the results of our study, CT following water-soluble CE is not a complicated method and could be useful in detecting occult AL for patients with a DS.

In this study, DM and steroid treatment, which were included as exclusion criteria in a previous report [12], and UC and CRT were not significantly correlated with the incidence of occult AL; however, these results might be simply because of the small sample size. Further confirmation is needed to assess the significance of these variables and to establish the optimal inclusion and exclusion criteria of EC. 
All patients who were diagnosed with an occult AL had no symptoms associated with AL during their postoperative course; however, if EC were performed for such patients, an occult AL would most likely develop into a symptomatic AL. To perform EC safely, both inclusion and exclusion criteria and methods to assess anastomosis should be standardized.

This study has several limitations. First, it is a single-center prospective observational study, with a very short study period and small overall sample size. For these reasons, we considered that it is statistically inappropriate to perform a multivariate analysis because such an analysis limits the accuracy of our outcome analysis. Second, as EC was not performed for this cohort, it is unproven whether radiological occult AL is correlated with any clinical symptoms after EC.

\section{Conclusions}

The incidence of occult AL on POD 7 in patients with a DS was as high as $40 \%$, and a hand-sewn anastomosis was a risk factor. When we considered the inclusion criteria of EC, stapled anastomosis was preferred. As water-soluble CE alone may have high false-negative radiological result rates, CT following CE should be chosen as a standard method to assess anastomosis integrity before EC. If the safety of EC is ensured by appropriate indication and examination, EC may be adopted as the standard treatment in the future.

\section{Declarations}

\section{Ethics approval and consent to participate}

Written informed consent was preoperatively obtained from all patients. The protocol for this prospective observational study was approved by the ethics committee of the University of Tsukuba Hospital (registration No. R01-104). The study conforms to the provisions of the Declaration of Helsinki in 1964 (as revised in Brazil in 2013).

\section{Availability of data and materials}

The datasets used and/or analyzed during the current study are available from the corresponding author on reasonable request.

\section{Competing interests}

The authors declare that they have no competing interests.

\section{Funding}

Only institutional sources were used for this study.

\section{Authors' contributions}


DK and TE contributed to the study design, data analysis, data interpretation, and manuscript preparation. $\mathrm{YO}, \mathrm{YO}, \mathrm{KH}, \mathrm{YA}, \mathrm{KT}, \mathrm{KO}, \mathrm{OS}$, and $\mathrm{TO}$ contributed to data analysis, drafted or revised of the manuscript, gave final approval of the version to be published, and have agreed to be accountable for all aspects of the work.

\section{References}

1. Matthiessen P, Hallböök O, Rutegard J, Sjodahl R. Population-based study of risk factors for postoperative death after anterior resection of the rectum. Br J Surg. 2006; 93:498-503.

2. Marusch F, Koch A, Schmidt U, Geisler S, Dralle H, Saeger HD, et al. Value of a protective stoma in low anterior resections for rectal cancer. Dis Colon Rectum. 2002; 45:1164-71.

3. Pakkastie TE, Ovaska JT, Pekkala ES, Luukkonen PE, Järvinen HJ. A randomized study of colostomies in low colorectal anastomoses. Eur J Surg. 1997; 163:929-33.

4. Poon RT, Chu KW, Ho JW, Chan CW, Law WL, Wong J. Prospective evaluation of selective defunctioning stoma for low anterior resection with total mesorectal excision. World J Surg. 1999; 23:463-7.

5. Dehni N, Schlegel RD, Cunningham C, Guigou M, Tiret E, Parc R. Influence of a defunctioning stoma on leakage rates after low colorectal anastomosis and colonic $\mathrm{J}$ pouch-anal anastomosis. $\mathrm{Br} \mathrm{J}$ Surg. 1998; 85:1114-7.

6. Karanjia ND, Corder AP, Holdworth PJ, Heald RJ. Risk of peritonitis and fatal septicaemia and the need to defunction the low anastomosis. Br J Surg. 1991; 78:196-8.

7. Guenaga KF, Lustosa SA, Saad SS, Saconato H, Matos D. lleostomy or colostomy for temporary decompression of colorectal anastomosis. Cochrane Database Syst Rev. 2007;(1):CD004647.

8. Gessler B, Haglind E, Angenete E. Loop ileostomies in colorectal cancer patients-morbidity and risk factors for nonreversal. J Surg Res. 2012; 178:708-14.

9. Gessler B, Haglind E, Angenete E. A temporary loop ileostomy affects renal function. Int J Colorectal Dis. 2014; 29:1131-5.

10. Tamura K, Matsuda K, Yokoyama S, Iwamoto H, Mizumoto Y, Murakami D, et al. Defunctioning loop ileostomy for rectal anastomoses: predictors of stoma outlet obstruction. Int J Colorectal Dis. 2019; 34:1141-5.

11. O'Leary DP, Fide CJ, Foy C, Lucarotti ME. Quality of life after low anterior resection with total mesorectal excision and temporary loop ileostomy for rectal carcinoma. Br J Surg. 2001; 88:121620.

12. Danielsen AK, Park J, Jansen JE, Bock D, Skullman S, Wedin A, et al. Early closure of a temporary ileostomy in patients with rectal cancer: a multicenter randomized controlled trial. Ann Surg. 2017; 265:284-90.

13. Menahem B, Lubrano J, Vallois A, Alves A. Early closure of defunctioning loop ileostomy: is it beneficial for the patient? a meta-analysis. World J Surg. 2018; 42:3171-8. 
14. Alves A, Panis $Y$, Lelong B, Dousset B, Benoist S, Vicaut E. Randomized clinical trial of early versus delayed temporary stoma closure after proctectomy. Br J Surg. 2008; 95:693-8.

15. Lasithiotakis K, Aghahoseini A, Alexander D. Is early reversal of defunctioning ileostomy a shorter, easier and less expensive operation? World J Surg. 2016; 40:1737-40.

16. Kanda Y. Investigation of the freely available easy-to-use software 'EZR' for medical statistics. Bone Marrow Transplant. 2013; 48:452-58.

17. Gouya H, Oudjit A, Leconte M, Coste J, Vignaux O, Dousset B, et al. CT antegrade colonography to assess proctectomy and temporary diverting ileostomy complications before early ileostomy takedown in patients with low rectal endometriosis. AJR Am J Roentgenol. 2012; 198:98-105.

\section{Tables}

Table 1: Patient characteristics

\begin{tabular}{l|l|c}
\multicolumn{2}{c}{ n=15 } \\
\hline Age & (years) & $56[27-70]$ \\
\hline Sex & $($ male $)$ & $12(80 \%)$ \\
\hline BMI & $\left(\mathrm{kg} / \mathrm{m}^{2)}\right.$ & $24[18-39]$ \\
\hline ASA-PS & 1 & $2(13 \%)$ \\
& 2 & $10(67 \%)$ \\
& 3 & $3(20 \%)$ \\
\hline Smoking & & $10(67 \%)$ \\
\hline DM & & $2(13 \%)$ \\
\hline Primary disease & Rectal cancer & $10(67 \%)$ \\
& UC & $4(27 \%)$ \\
& FAP & $1(7 \%)$ \\
\hline
\end{tabular}

BMI: body mass index; ASA-PS: American Society of Anesthesiology physical status; DM: diabetes mellitus; UC: ulcerative colitis; FAP: familial adenomatous polyposis

Table 2: Treatment characteristics

\begin{tabular}{l|l|c}
\multicolumn{2}{c}{$\mathbf{n = 1 5}$} \\
\hline Preoperative treatment & NAC & $1(7 \%)$ \\
& CRT & $3(20 \%)$ \\
& Steroid & $2(13 \%)$ \\
\hline Operation & LAR & $4(27 \%)$ \\
& ISR & $6(40 \%)$ \\
& IPAA & $5(33 \%)$ \\
\hline MIS & Laparoscopy & $12(80 \%)$ \\
& TaTME & $8(53 \%)$ \\
& Robot & $1(7 \%)$ \\
\hline Anastomosis & Stapled & $8(53 \%)$ \\
& Hand-sewn & $7(47 \%)$ \\
\hline Distance of anastomosis & (cm from AV) & $4[2-6]$ \\
\hline
\end{tabular}


NAC: neoadjuvant chemotherapy; CRT: chemoradiotherapy; LAR: low anterior resection; ISR: intersphincteric resection; IPAA: total colectomy with ileal pouch-anal anastomosis; MIS: minimally invasive surgery; TaTME: transanal total mesorectal excision; AV: anal verge

Table 3: Relationship between each variable and the incidence of occult AL on postoperative day 7

n Occult AL OR [95\%CI] $P$ value*

\begin{tabular}{|c|c|c|c|c|c|}
\hline Age (years) & $\begin{array}{l}<60 \\
60 \leq\end{array}$ & $\begin{array}{l}9 \\
6\end{array}$ & $\begin{array}{l}5(56 \%) \\
1(17 \%)\end{array}$ & $\begin{array}{c}0.181 \\
{[0.003-2.69]}\end{array}$ & 0.287 \\
\hline Sex & $\begin{array}{c}\text { Male } \\
\text { Female }\end{array}$ & $\begin{array}{c}12 \\
3\end{array}$ & $\begin{array}{l}5(42 \%) \\
1(33 \%)\end{array}$ & $\begin{array}{c}1.40 \\
{[0.057-101]}\end{array}$ & 1 \\
\hline BMI $\left(\mathrm{kg} / \mathrm{m}^{2}\right)$ & $\begin{array}{l}<25 \\
25 \leq\end{array}$ & $\begin{array}{l}8 \\
7\end{array}$ & $\begin{array}{l}3(38 \%) \\
3(43 \%)\end{array}$ & $\begin{array}{c}1.23 \\
{[0.101-15.4]}\end{array}$ & 1 \\
\hline ASA-PS & $\begin{array}{c}1-2 \\
3\end{array}$ & $\begin{array}{c}12 \\
3\end{array}$ & $\begin{array}{l}4(33 \%) \\
2(67 \%)\end{array}$ & $\begin{array}{c}3.62 \\
{[0.147-264]}\end{array}$ & 0.525 \\
\hline Smoking & $\begin{array}{l}\text { Yes } \\
\text { No }\end{array}$ & $\begin{array}{c}10 \\
5\end{array}$ & $\begin{array}{l}4(40 \%) \\
2(40 \%)\end{array}$ & $\begin{array}{c}1 \\
{[0.073-17.3]}\end{array}$ & 1 \\
\hline $\mathrm{DM}$ & $\begin{array}{l}\text { Yes } \\
\text { No }\end{array}$ & $\begin{array}{c}2 \\
13\end{array}$ & $\begin{array}{c}0 \\
6(46 \%)\end{array}$ & $\begin{array}{c}0 \\
{[0-8.04]}\end{array}$ & 0.486 \\
\hline UC & $\begin{array}{l}\text { Yes } \\
\text { No }\end{array}$ & $\begin{array}{c}4 \\
11\end{array}$ & $\begin{array}{l}2(50 \%) \\
4(36 \%)\end{array}$ & $\begin{array}{c}1.68 \\
{[0.089-32.5]}\end{array}$ & 1 \\
\hline CRT & $\begin{array}{l}\text { Yes } \\
\text { No }\end{array}$ & $\begin{array}{c}3 \\
12\end{array}$ & $\begin{array}{l}1 \text { (33\%) } \\
5(42 \%)\end{array}$ & $\begin{array}{c}0.716 \\
{[0.010-17.6]}\end{array}$ & 1 \\
\hline Steroid & $\begin{array}{l}\text { Yes } \\
\text { No }\end{array}$ & $\begin{array}{c}2 \\
13\end{array}$ & $\begin{array}{l}1(50 \%) \\
5(38 \%)\end{array}$ & $\begin{array}{c}1.55 \\
{[0.017-141]}\end{array}$ & 1 \\
\hline Anastomosis & $\begin{array}{c}\text { Stapled } \\
\text { Hand-sewn }\end{array}$ & $\begin{array}{l}8 \\
7\end{array}$ & $\begin{array}{l}1(13 \%) \\
5(71 \%)\end{array}$ & $\begin{array}{c}13.6 \\
{[0.865-934]}\end{array}$ & $<0.05$ \\
\hline $\begin{array}{l}\text { Distance of anastomosis } \\
\text { from } \mathrm{AV}(\mathrm{cm})\end{array}$ & $\begin{array}{l}<4 \\
4 \leq\end{array}$ & $\begin{array}{l}6 \\
9\end{array}$ & $\begin{array}{l}4(67 \%) \\
2(22 \%)\end{array}$ & $\begin{array}{c}0.167 \\
{[0.008-2.17]}\end{array}$ & 0.136 \\
\hline
\end{tabular}

BMI: body mass index; ASA-PS: American Society of Anesthesiology physical status; DM: diabetes mellitus; UC: ulcerative colitis; CRT: chemoradiotherapy; AV: anal verge; AL: anastomotic leakage; OR: odds ratio; CI: confidential interval (*Fisher's exact test)

Table 4: Hematological examination results on postoperative day 7

\section{Entire cohort}

Occult AL

Non-occult AL

\begin{tabular}{c|c|c|c}
\hline WBC (/pl) & $7400[5800-12500]$ & $6900[5800-12500]$ & $7500[5800-11200]$ \\
\hline CRP (mg/dl) & $1.75[0.18-9.06]$ & $1.39[0.18-9.06]$ & $1.99[0.60-8.32]$ \\
\hline
\end{tabular}

AL anastomotic leakage; WBC: white blood cell; CRP: C-reactive protein. 


\section{Figures}

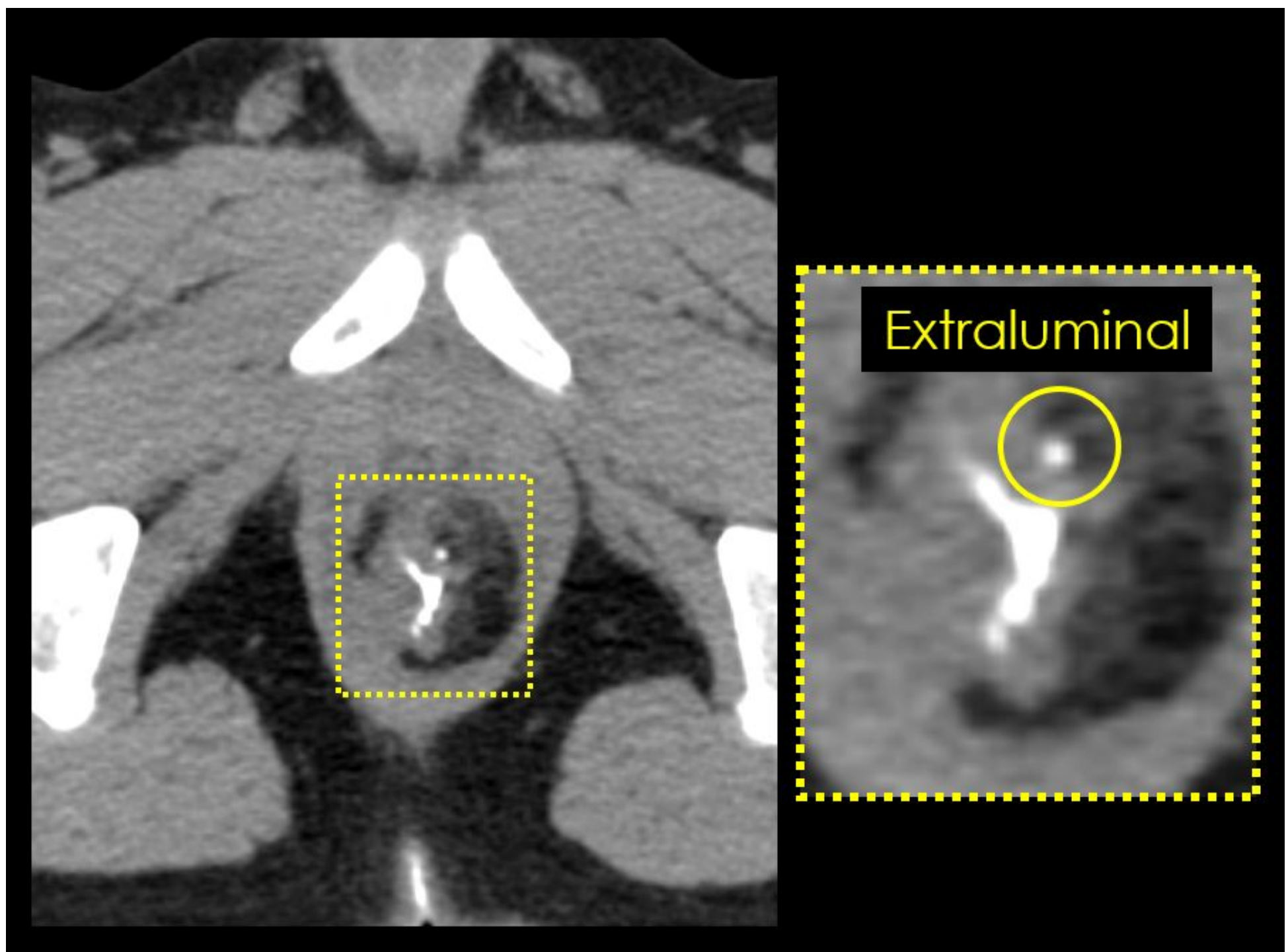

\section{Figure 1}

Pelvic plain computed tomography (CT) without contrast medium. Retrograde infusion of Gastrografin ${ }^{\circledR}$ was detected extraluminally on CT image, and this case was diagnosed as an occult anastomotic leakage 